\title{
General and Health-Related Internet Use Among Cancer Survivors in the United States: A 2013-2018 Cross-Sectional Analysis
}

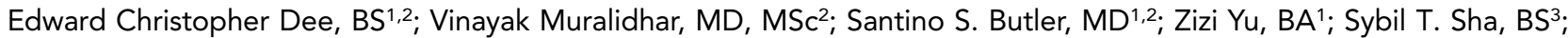 \\ Brandon A. Mahal, MD ${ }^{4,5}$; Paul L. Nguyen, MD²; and Nina N. Sanford, MD 6
}

\section{ABSTRACT}

Background: A significant proportion of cancer survivors endorse ongoing health information needs and may use the internet to access information. We assessed patterns and predictors of general and healthspecific internet use among cancer survivors. Methods: Using data from the National Health Interview Survey (NHIS), which was administered in 2013 through 2018, for adults reporting a cancer diagnosis, sample weight-adjusted estimates defined prevalence and multivariable logistic regressions defined adjusted odds ratios (aORs) of general and health-specific internet use, adjusting for relevant sociodemographic covariates, including healthcare satisfaction as the primary independent variable. The analysis for health-specific internet use was also repeated including a sex (female vs male)*healthcare satisfaction (very satisfied/somewhat satisfied vs somewhat dissatisfied/very dissatisfied) interaction term. Results: Among 12,970 survivors of cancer, general and health-specific internet use increased from 2013 to 2018 (from $63.2 \%$ to $70.8 \%$ and from $46.8 \%$ to $52.2 \%$, respectively; $P<.05$ for both). Survivors who were very dissatisfied with healthcare were more likely to use the internet for health information compared with those who were very satisfied ( $59.5 \%$ vs $48.0 \%$; aOR, 1.78 ; $95 \% \mathrm{Cl}, 1.20-2.64$; $P=.004)$. Younger age, female sex, higher educational attainment, and higher socioeconomic status were all associated with increased reported use of the internet for both general and health-specific purposes $\left(P<.001\right.$ for all). There was a significant sex ${ }^{\star}$ healthcare satisfaction interaction $(P=.009)$ such that for female survivors, healthcare dissatisfaction was associated with higher odds of health-specific internet use (61.4\% vs $52.5 \% ; P<.001$; men, $P=.97)$. No association was found between healthcare satisfaction and general internet use $(P=.42)$. Conclusions: The increasing proportion of survivors of cancer using the internet for health-specific information may be associated with selfreported dissatisfaction with healthcare. Efforts are needed to improve both access to the internet and the quality of cancer-relevant online health information, and to enhance patients' online health literacy.

J Natl Compr Canc Netw 2020;18(11):1468-1475 doi: $10.6004 /$ jnccn.2020.7591

\footnotetext{
${ }^{1}$ Harvard Medical School, and ${ }^{2}$ Dana-Farber Cancer Institute, Boston, Massachusetts; ${ }^{3}$ Geisel School of Medicine, Hanover, New Hampshire; ${ }^{4}$ Department of Radiation Oncology, University of Miami Miller School of Medicine, and ${ }^{5}$ Office of Community Outreach and Engagement, Sylvester Comprehensive Cancer Center, Miami, Florida; and ${ }^{6}$ Department of Radiation Oncology, University of Texas Southwestern Medical Center, Dallas, Texas.
}

\section{Background}

Most individuals diagnosed with cancer in the United States survive $\geq 5$ years, ${ }^{1}$ contributing to an increasing population of cancer survivors. ${ }^{2}$ A significant proportion of these individuals endorse ongoing health information needs, ${ }^{3}$ which may be different for patients with newly diagnosed cancers, who may seek information regarding treatment options and acute adverse effects, versus those who have completed treatment and may be more concerned about risks of recurrence, follow-up care, and long-term toxicities. ${ }^{4-6}$ Among cancer survivors, unmet information needs exist and access to high-quality and relevant health information has been associated with improved psychosocial outcomes and overall healthrelated quality of life. ${ }^{7-10}$ Over the past several decades, the internet has played an increasing role in providing cancer survivors with health information ${ }^{11}$ and has revolutionized the way in which information is shared and accessed. Currently, approximately $90 \%$ of the general US population reports internet use. ${ }^{12}$

Although medically sponsored websites with evidencebased guidelines exist, the internet can also serve as a platform for dissemination of potentially harmful medical misinformation. ${ }^{11,13}$ Studies regarding the quality of online health information in oncology ${ }^{14-17}$ and other fields ${ }^{18,19}$ have shown the accuracy of such pages to be variable, with many online resources with poor-quality information garnering high-volume readership. ${ }^{20}$ In addition, commercial websites, some of which are run by companies that pay to rank themselves among the top hits for healthrelated searches, ${ }^{18}$ may provide information biased toward the use of particular products or treatments. ${ }^{21}$ Furthermore, evidence-based academic online resources may require educational attainment above the national average in order to comprehend the information, possibly leading to confusion. ${ }^{22}$

Given that online information can positively or negatively affect one's decision to seek care, engage in screening,

See page 1586 for related commentary. 
or practice healthy lifestyle choices, ${ }^{23-25}$ it is important to understand how patients and survivors of cancer use the internet as a source of health information. Therefore, we used a nationally representative survey to assess recent patterns and predictors of internet use to obtain health information, compared with general internet use, among patients and survivors of cancer.

\section{Methods}

\section{Data Source}

The National Health Interview Survey (NHIS) is a crosssectional household survey that collects data on a range of health indicators for noninstitutionalized, civilian adults. ${ }^{26}$ The NHIS, administered by the National Center for Health Statistics (NCHS) and the CDC, conducts inperson interviews with a multistage probability-selected and nationally representative sample of $>100,000$ US participants spanning 45,000 households. ${ }^{26}$ Sample weights allow inference on national prevalence; harmonized data were obtained through the Integrated Public Use Microdata Series (IPUMS) Health Survey database. ${ }^{27}$

\section{Study Cohort}

The study population included adults aged $\geq 18$ years sampled from 2013 through 2018 reporting a history of cancer. This 6-year time interval represents the only years the NHIS included questions regarding both internet use and healthcare satisfaction. The population was specifically defined as patients who were queried regarding their cancer history and responded yes when asked if they had ever been told "by a doctor or other health professional that [they] had cancer or a malignancy of any kind." Those who reported a diagnosis of nonmelanoma skin cancer were excluded, consistent with other cancer survivorship studies. ${ }^{28-31}$ We included relevant sociodemographic variables captured via NHIS interview, including year of survey, age, sex, sexual orientation (straight or nonstraight), region of residency (Northeast, North Central/Midwest, South, or West), years since cancer diagnosis (calculated as age at time of survey minus age at cancer diagnosis), self-identified race/ethnicity (White, Black/African American, American Indian/Alaska Native, Asian, or multiple race), marital status (married or not married), highest educational degree (grade 8 , grade 12 without diploma, high school diploma, some college, completed bachelor's degree, or advanced degree), citizenship status (US citizen or noncitizen), socioeconomic status (ratio of family income to poverty threshold), selfreported health status, and insurance status (with or without insurance coverage).

Internet Use and Healthcare Satisfaction

From 2013 through 2018, the NHIS included the following questions regarding internet use: "Do you use the internet?" and "Have you looked up health information on the internet in the past 12 months?" Responses were binary (yes or no). Participants were also queried regarding general healthcare satisfaction via the question, "How satisfied are you with healthcare in the past 12 months?" Responses to this question included "very satisfied," "somewhat satisfied," "somewhat dissatisfied," and "very dissatisfied."

\section{Statistical Analyses}

Multivariable logistic regression defined adjusted odds ratios (aOR) with 95\% confidence intervals for general and health-specific internet use. The primary independent variable was healthcare satisfaction (very satisfied [referent] vs somewhat satisfied vs somewhat dissatisfied vs very dissatisfied). Other sociodemographic variables included in the model were year of survey, age, sex, sexual orientation, region of residence, years since diagnosis, race/ethnicity, marital status, educational attainment, citizenship status, socioeconomic status, self-reported health status, and health insurance status. In a separate model, given previous studies suggesting associations between healthcare satisfaction and sex, ${ }^{32,33}$ the analysis for health-specific internet use was repeated including a sex (female vs male)*healthcare satisfaction (very satisfied/somewhat satisfied vs somewhat dissatisfied/ very dissatisfied) interaction term to assess whether the association between healthcare satisfaction and internet use varied by sex.

Analyses were performed with STATA/SE, version 15.1 (StataCorp LLP). The Dana-Farber/Harvard Cancer Center and University of Texas Southwestern Medical Center Institutional Review Boards deemed the study exempt given the use of public deidentified data. Methods are subject to reporting bias due to the nature of the NHIS. Data and analyses are presented in accordance with the Strengthening the Reporting of Observational Studies in Epidemiology (STROBE) reporting guideline for cross-sectional studies. ${ }^{34}$

\section{Results}

\section{Patient Population}

Among 12,970 cancer survivors surveyed from 2013 through 2018, 7,615 (53.3\%) were aged $\geq 65$ years, 7,762 (57.4\%) were women, and 1,839 (13.0\%) did not self-identify as White. More than two-thirds $(n=8,730 ; 66.3 \%)$ were diagnosed $>5$ years before the survey. Furthermore, 12,584 (97.0\%) had health insurance and 5,008 (40.3\%) described their health status as "excellent" or "very good" (Table 1).

\section{Variables Associated With General Internet Use}

Among 12,970 adult survivors of cancer, 8,151 (67.9\%) reported general internet use. The proportion of cancer survivors reporting general internet use increased over 


\section{Table 1. Baseline Cohort Demographics}

\section{Characteristic}

Raw n (Raw\%/Weighted\%)

$\begin{array}{ll}\text { Total, } \mathrm{n} & 12,970\end{array}$

Year of survey

\begin{tabular}{ll}
\hline 2013 & $2,042(15.7 / 15.0)$ \\
\hline 2014 & $2,315(17.9 / 15.4)$ \\
\hline 2015 & $2,168(16.7 / 15.8)$ \\
\hline 2016 & $2,426(18.7 / 17.7)$ \\
\hline 2017 & $2,057(15.9 / 18.2)$ \\
\hline 2018 & $1,962(15.1 / 18.0)$
\end{tabular}

Age, $y$

\begin{tabular}{lc}
$18-39$ & $810(6.3 / 7.2)$ \\
\hline $40-64$ & $4,545(35.0 / 39.6)$ \\
\hline$\geq 65$ & $7,615(58.7 / 53.3)$
\end{tabular}

Sex

\begin{tabular}{ll}
\hline Male & $5,208(40.2 / 42.6)$ \\
\hline Female & $7,762(59.9 / 57.4)$
\end{tabular}

Sexual orientation

\begin{tabular}{lc}
\hline Straight & $12,614(97.3 / 97.5)$ \\
\hline Nonstraight & $356(2.7 / 2.6)$
\end{tabular}

Region

Northeast

$2,262(17.7 / 18.3)$

North Central/Midwest

$3,052(23.5 / 23.6)$

South

$4,559(35.2 / 37.2)$

West

$3,097(23.9 / 21.0)$

Years since diagnosis

\begin{tabular}{ll}
$\leq 2$ & $2,900(22.4 / 23.0)$ \\
\hline $3-5$ & $1,340(10.3 / 10.7)$ \\
$>5$ & $8,730(67.3 / 66.3)$
\end{tabular}

Race/Ethnicity

White $11,131(85.8 / 87.0)$

Black/African American

$1,198(9.2 / 8.1)$

American Indian/Alaska Native

$95(0.7 / 0.7)$

Asian

$305(2.4 / 2.7)$

Multiple race

$241(1.9 / 1.4)$

Marital status

\begin{tabular}{ll} 
Married & $5,878(45.3 / 59.3)$ \\
\hline Not married & $7,092(54.7 / 40.7)$
\end{tabular}

Highest educational degree

\begin{tabular}{lc}
\hline Grade 8 & $668(5.2 / 4.4)$ \\
\hline Grade 12, no diploma & $1,135(8.8 / 7.9)$ \\
\hline High school diploma & $3,419(26.4 / 26.3)$ \\
\hline Some college & $3,963(30.6 / 30.0)$ \\
\hline Bachelor's degree & $2,223(17.1 / 18.6)$ \\
\hline Advanced degree & $1,562(12.0 / 12.9)$
\end{tabular}

(continued)

\section{Table 1. Baseline Cohort Demographics (cont.)}

\section{Characteristic}

Raw n (Raw\%/Weighted\%)

Citizenship status

$$
\text { US citizen }
$$

$12,727(98.1 / 97.8)$

Non-US citizen

$243(1.9 / 2.2)$

Socioeconomic status ${ }^{a}$

\begin{tabular}{ll}
\hline$<1.00$ & $1,624(12.5 / 9.4)$ \\
\hline $1.00-1.99$ & $2,641(20.4 / 17.3)$ \\
\hline $2.00-3.99$ & $3,972(30.6 / 30.7)$ \\
$\geq 4.00$ & $4,733(36.5 / 42.6)$
\end{tabular}

Self-reported health status

Excellent 1,541 (11.9/13.0)

Very good $\quad 3,467(26.7 / 27.3)$

Good 4,334 (33.4/32.6)

Fair 2,611 (20.1/19.3)

Poor $\quad 1,017(7.8 / 7.8)$

Insurance status

\begin{tabular}{lc}
\hline Coverage & $12,584(97.0 / 97.0)$ \\
\hline No coverage & $386(3.0 / 3.0)$
\end{tabular}

Satisfaction with healthcare

Very satisfied 9,386 (72.4/72.6)

Somewhat satisfied $\quad 2,864(22.1 / 22.1)$

Somewhat dissatisfied $\quad 473(3.7 / 3.4)$

Very dissatisfied 247 (1.9/1.9)

Abbreviation: NHIS, National Health Interview Survey.

aRatio of family income to poverty threshold.

time, from $63.2 \%$ in 2013 to $70.8 \%$ in 2018 (aOR for 2018 vs $2013,1.48 ; 95 \% \mathrm{CI}, 1.21-1.82 ; P<.001)$. Younger age (18-39 vs $\geq 65$ years), female sex, White race (vs Black/ African American), higher educational attainment, and higher socioeconomic status were all associated with increased reported use of general internet use $(P<.001$ for all; Table 2). There was no association between years since diagnosis and general internet use $(P=.38)$. Lastly, those describing their overall health status as poor were less likely to report general internet use compared with those describing excellent overall health status $(44.0 \%$ vs $85.3 \%$; aOR, 0.28 ; $95 \%$ CI, $0.21-0.37$; $P<.001)$.

\section{Variables Associated With Health-Specific}

Internet Use

Among 12,970 adult survivors of cancer, 5,818 (48.9\%) reported health-specific internet use. Health-specific internet use in this population also increased from $46.8 \%$ in 2013 to $52.2 \%$ in 2018 (2018 vs 2013 aOR, 1.22; 95\% CI, 1.03-1.46; $P=.023$; Figure 1$)$. Younger age ( $18-39$ vs $\geq 65$ years), female sex, White race (vs Black/African American), higher educational attainment, and higher socioeconomic 


\section{Table 2. Preference of and Multivariable aORs for Internet Use in Past 12 Months $(\mathbf{N}=12,970)$}

\begin{tabular}{|c|c|c|c|c|c|c|}
\hline \multirow[b]{2}{*}{ Characteristic } & \multirow{2}{*}{$\begin{array}{l}\text { General Internet } \\
\text { Use, Raw n } \\
\text { (Raw\% of Row } \\
\text { Total/Weighted\%) }\end{array}$} & \multicolumn{2}{|c|}{$\begin{array}{l}\text { Multivariable } \\
\text { Adjusted Odds }\end{array}$} & \multirow{2}{*}{$\begin{array}{c}\text { Health-Specific Internet } \\
\text { Use, Raw n } \\
\text { (Raw \% of Row } \\
\text { Total/Weighted \%) }\end{array}$} & \multicolumn{2}{|c|}{$\begin{array}{l}\text { Multivariable } \\
\text { Adjusted Odds }\end{array}$} \\
\hline & & aOR $(95 \% \mathrm{Cl})$ & $P$ Value & & aOR $(95 \% \mathrm{Cl})$ & $P$ Value \\
\hline \multicolumn{7}{|l|}{ Year } \\
\hline 2013 & $1,185(58.0 / 63.2)$ & Ref & & $862(42.2 / 46.8)$ & Ref & \\
\hline 2016 & $1,592(65.6 / 70.2)$ & $1.34(1.10-1.64)$ & .004 & $1,130(46.6 / 50.8)$ & $1.11(0.93-1.33)$ & .26 \\
\hline 2017 & $1,386(67.4 / 70.3)$ & $1.34(1.09-1.64)$ & .005 & $999(48.6 / 50.3)$ & $1.09(0.92-1.30)$ & .33 \\
\hline 2018 & $1,320(67.3 / 70.8)$ & $1.48(1.21-1.82)$ & $<.001$ & $977(49.8 / 52.2)$ & $1.22(1.03-1.46)$ & .023 \\
\hline \multicolumn{7}{|l|}{ Age, y } \\
\hline \multicolumn{7}{|l|}{ Sex } \\
\hline Male & $3,075(59.0 / 65.1)$ & Ref & & $2,022(38.8 / 43.2)$ & Ref & \\
\hline Female & $5,076(65.4 / 70.0)$ & $1.38(1.22-1.55)$ & $<.001$ & $3,796(48.9 / 53.1)$ & $1.68(1.50-1.87)$ & $<.001$ \\
\hline \multicolumn{7}{|l|}{ Sexual orientation } \\
\hline Straight & $7,864(62.3 / 67.4)$ & Ref & & $5,575(44.2 / 48.4)$ & Ref & \\
\hline Nonstraight & $287(80.6 / 84.9)$ & $1.69(1.13-2.52)$ & .011 & $243(68.3 / 68.2)$ & $1.59(1.14-2.21)$ & .006 \\
\hline \multicolumn{7}{|l|}{ Region } \\
\hline Northeast & $1,432(63.3 / 68.0)$ & Ref & & $1,030(45.5 / 49.8)$ & Ref & \\
\hline North Central/Midwest & $1,932(63.3 / 68.8)$ & $1.13(0.94-1.36)$ & .18 & $1,366(44.8 / 48.9)$ & $1.02(0.87-1.20)$ & .82 \\
\hline \multicolumn{7}{|l|}{ Race/Ethnicity } \\
\hline White & $7,239(65.0 / 69.7)$ & Ref & & $5,194(46.7 / 50.3)$ & Ref & \\
\hline Black/African American & $538(44.9 / 51.0)$ & $0.61(0.50-0.74)$ & $<.001$ & $350(29.2 / 35.1)$ & $0.69(0.57-0.83)$ & $<.001$ \\
\hline American Indian/Alaska Native & $55(57.9 / 67.8)$ & $0.80(0.46-1.41)$ & .45 & $34(35.8 / 39.7)$ & $0.54(0.28-1.05)$ & .068 \\
\hline Asian & $179(58.7 / 63.4)$ & $0.57(0.39-0.83)$ & .003 & $124(40.7 / 46.5)$ & $0.71(0.49-1.02)$ & .063 \\
\hline Multiple race & $140(58.1 / 59.9)$ & $0.76(0.47-1.24)$ & .27 & $116(48.1 / 51.6)$ & $1.24(0.83-1.84)$ & .30 \\
\hline \multicolumn{7}{|l|}{ Marital status } \\
\hline Married & $4,205(71.5 / 74.5)$ & Ref & & $3,005(51.1 / 53.7)$ & Ref & \\
\hline Not married & $3,946(55.6 / 58.2)$ & $0.67(0.59-0.75)$ & $<.001$ & $2,813(39.7 / 41.8)$ & $0.77(0.70-0.86)$ & $<.001$ \\
\hline \multicolumn{7}{|l|}{ Highest educational degree } \\
\hline Grade 8 & $77(11.5 / 14.4)$ & Ref & & $38(5.7 / 8.5)$ & Ref & \\
\hline Grade 12, no diploma & $336(29.6 / 33.4)$ & $2.24(1.51-3.33)$ & $<.001$ & $194(17.1 / 19.2)$ & $1.95(1.21-3.16)$ & .006 \\
\hline High school diploma & $1,620(47.4 / 52.8)$ & $3.92(2.71-5.67)$ & $<.001$ & $1,047(30.6 / 34.4)$ & $3.78(2.40-5.97)$ & $<.001$ \\
\hline Some college & $2,879(72.7 / 76.7)$ & $9.93(6.85-14.39)$ & $<.001$ & $2,069(52.2 / 55.1)$ & $7.66(4.86-12.08)$ & $<.001$ \\
\hline Bachelor's degree & $1,860(83.7 / 86.4)$ & $15.20(10.27-22.50)$ & $<.001$ & $1,374(61.8 / 64.2)$ & $10.27(6.44-16.37)$ & $<.001$ \\
\hline Advanced degree & $1,379(88.3 / 91.0)$ & $23.24(15.33-35.23)$ & $<.001$ & $1,096(70.2 / 73.7)$ & $17.17(10.67-27.63)$ & $<.001$ \\
\hline
\end{tabular}




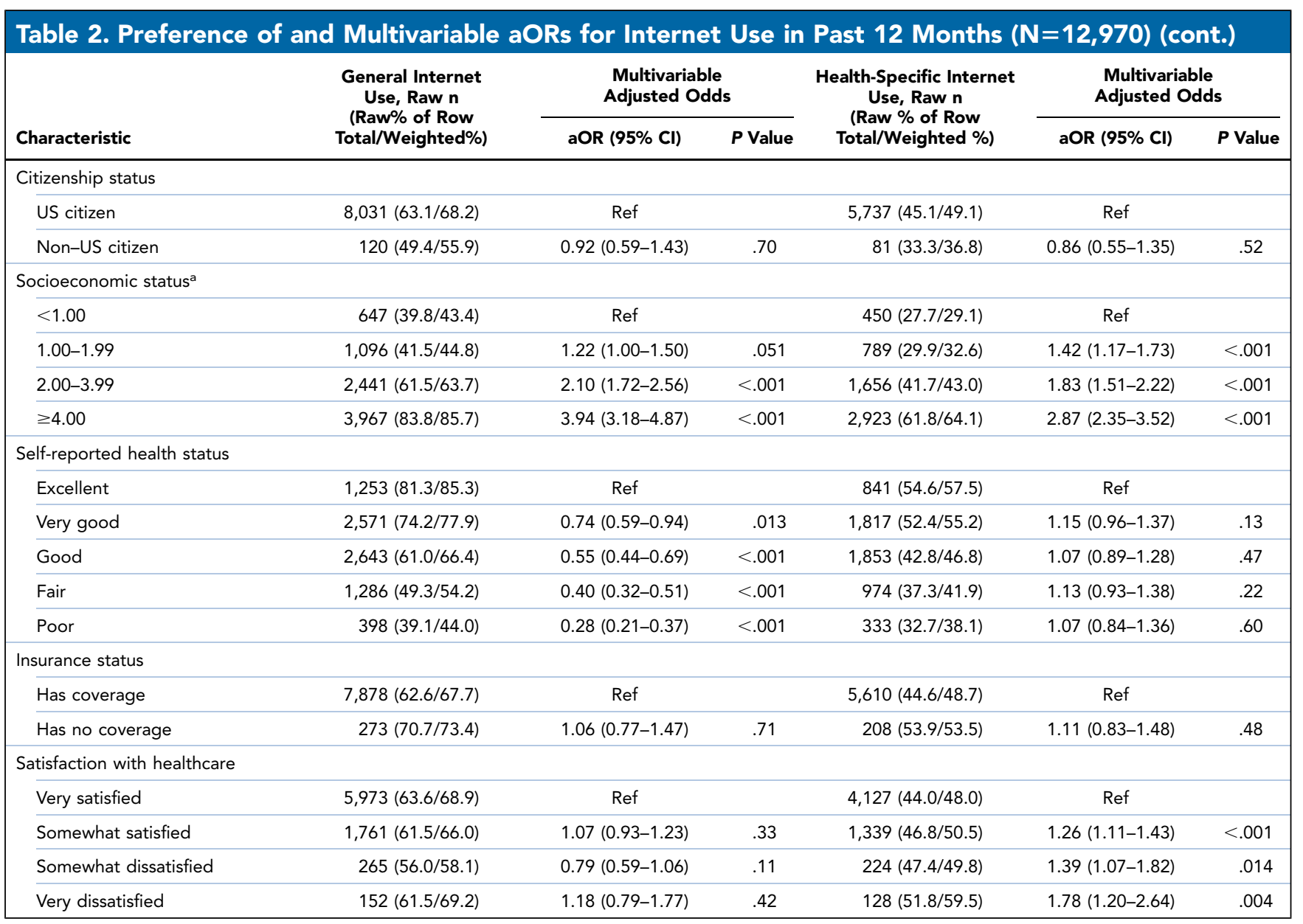

Abbreviations: aOR, adjusted odds ratio; NHIS, National Health Interview Survey.

anatio of family income to poverty threshold.

status were all associated with increased reported use of internet for health-specific purposes $(P<.001$ for all; Table 2). In contrast to general internet use patterns, health-specific internet use was lower among patients $>5$ years from their cancer diagnosis, compared with those who were $\leq 2$ years from diagnosis $(47.5 \%$ vs $50.3 \%$; aOR, $0.85 ; 95 \%$ CI, $0.75-0.97 ; P=.013)$. There was no difference in health-related internet use among cancer survivors reporting poor versus excellent overall health status (38.1\% vs $57.5 \%$; aOR, 1.07 ; $95 \% \mathrm{CI}, 0.84-1.36$; $P=.60$ ).

Notably, cancer survivors who were very dissatisfied with healthcare were $77.7 \%$ more likely to use the internet for health information compared with those who were very satisfied (59.5\% vs $48.0 \%$; aOR, 1.78 ; $95 \% \mathrm{CI}, 1.20-2.64$; $P=.004$; Figure 2A). Furthermore, there was a significant sex*healthcare satisfaction interaction $(P=.009)$ such that for female survivors of cancer $(n=7,762)$, healthcare dissatisfaction was associated with higher odds of healthspecific internet use $(61.4 \%$ vs $52.5 \%$; aOR, 1.74 ; $95 \% \mathrm{CI}$, $1.32-2.29 ; P<.001)$ but not for male survivors of cancer $(\mathrm{n}=5,208)(39.2 \%$ vs $43.4 \%$; aOR, 1.01 ; $95 \%$ CI, $0.68-1.50$;
$P=.97$ ) (Figure $2 \mathrm{~B}$ ). In contrast, there was no association between general internet use and healthcare satisfaction (69.2\% vs $68.9 \%$; aOR, 1.18; 95\% CI, 0.79-1.77; $P=.42$ ).

\section{Discussion}

In this nationally representative US survey of 12,970 adult cancer survivors surveyed from 2013 through 2018, approximately half use the internet as a health information source, with the proportion increasing over time. Sociodemographic factors associated with higher odds of reporting both general and health-specific internet use included white race, younger age, female sex, greater educational attainment, and higher income. Notably, greater dissatisfaction with healthcare was associated with higher odds of reporting health-specific internet use only, and not general internet use.

Because of increasing access to health information facilitated by the internet, healthcare providers may no longer represent the primary source of medical information. ${ }^{24,35}$ We found important sociodemographic disparities in internet use among cancer survivors. By distributing 


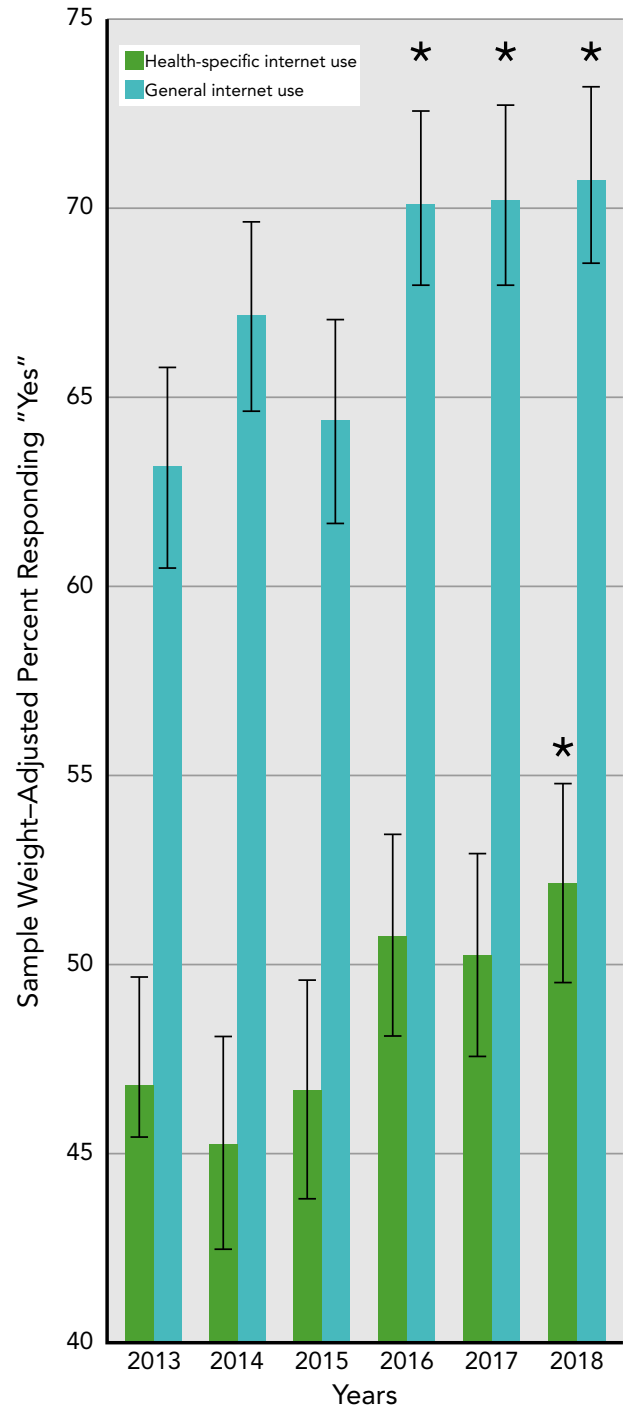

Figure 1. Sample weight-adjusted prevalence of general and healthspecific internet use among 12,970 cancer survivors from 2013 through 2018.

${ }^{*} P \leq 05$ on multivariable logistic regression-defined adjusted odds ratio with referent group $=2013$. Solid bars represent $95 \%$ confidence intervals for sample weight-adjusted estimates.

health information ${ }^{24}$ and empowering patients, ${ }^{36}$ the internet can help satisfy ongoing health information needs, which has been associated with improved coping skills, satisfaction, and overall quality of life..$^{7-9,37}$ Therefore, access to online health information may help patients obtain greater awareness and engage in active participation in their survivorship care. ${ }^{38}$ However, our study found that certain sociodemographic groups, notably those traditionally representing medically disadvantaged populations, report lower odds of internet use. These findings suggest unequal access to the internet among already vulnerable groups. Prior work has shown that survivors of cancer who experienced greater difficulty in accessing health information reported decreased confidence in their own ability to address health-related issues. ${ }^{7,39}$ Identifying and addressing these information disparities is important, because cancer survivors with unfulfilled information needs may be more likely to experience psychosocial distress. ${ }^{7,10}$ Efforts therefore should be undertaken to understand barriers to internet use, improve accessibility of the internet, and equip patients who are unable to use the internet to obtain health information with other sources of patient education.

Cancer survivors often integrate information from multiple sources when assessing the credibility of information found online..$^{40,41}$ The utility of increased access to health information is incumbent upon appropriate use by its consumers. eHealth literacy, defined as "the ability to seek, find, understand, and appraise health information from electronic sources and apply the knowledge gained to addressing or solving a health problem," is an increasingly important parameter of health literacy, evidenced by the prevalence of internet use among cancer survivors. ${ }^{42}$ Therefore, efforts should be made to both assess and enhance eHealth literacy. For example, validated scales ${ }^{43,44}$ on eHealth literacy may help measure and therefore mitigate potential gaps in this increasingly important mechanism for information gathering among cancer survivors.

Although the internet may contain useful health information, the quality of many websites is unregulated. ${ }^{14-19,22,45,46}$ Perhaps ironically, peer-reviewed medical information, such as in the form of journal articles or society guidelines, may be financially restricted and therefore not easily accessible to the general population. Given that misinformation or inappropriate interpretation of information may impact health-related choices among patients with cancer, ${ }^{23-25}$ our finding of increasing healthspecific internet use among cancer survivors with later year of survey underscores the value of improving the quality of health information websites. ${ }^{14,15,46}$

Notably, our findings showed that cancer survivors who were very dissatisfied with healthcare were $78 \%$ more likely to use the internet as a health information source compared with others, an association that was greater among women who reported dissatisfaction with healthcare. Previous research has shown that patients with cancer are often dissatisfied with the quality and extent of information provided by healthcare providers, ${ }^{47}$ and as a result may integrate information from multiple other sources when making decisions regarding their care. ${ }^{40,41}$ These findings further underscore the value of efforts to make quality online health information available and to enhance eHealth literacy. ${ }^{11,48}$

Our findings must be interpreted in light of the study's limitations. First, the survey design is subject to participant recall bias. Specifically, history of cancer diagnosis was self-reported and not physician-verified. 
A

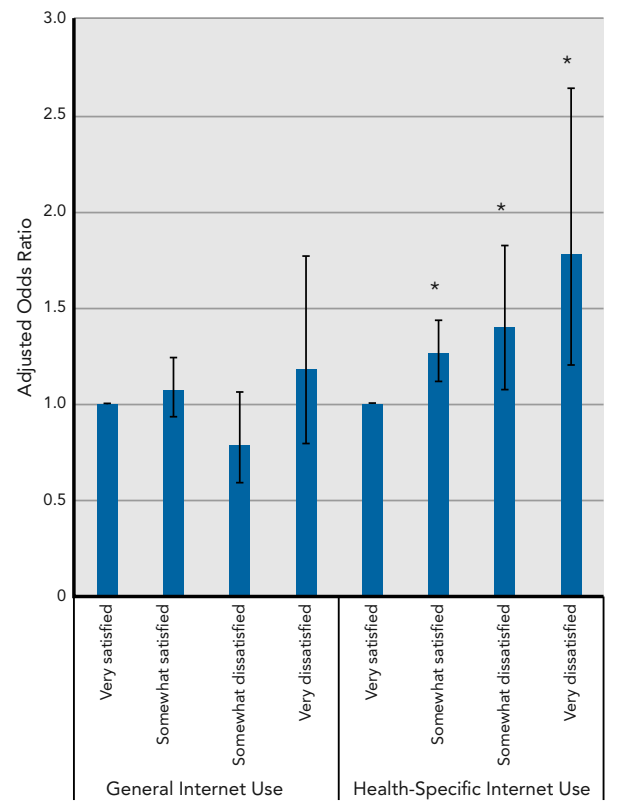

B

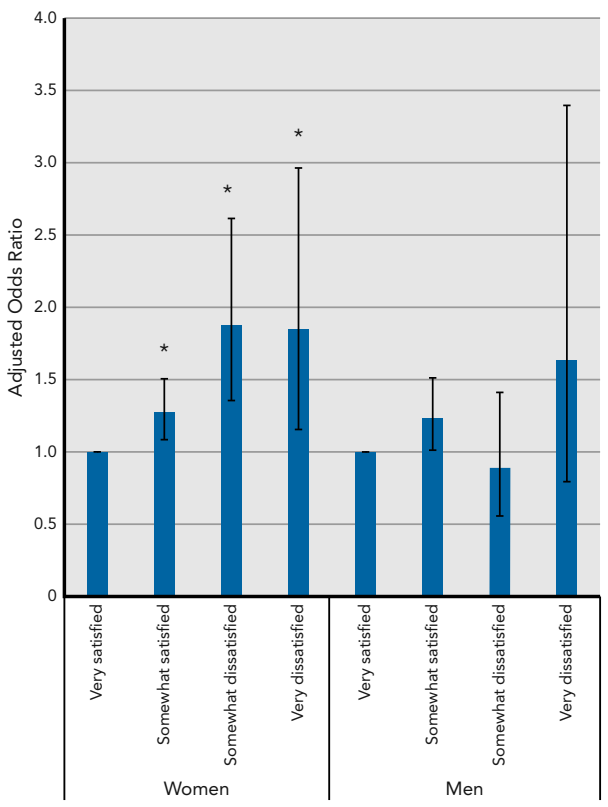

Figure 2. Adjusted odds ratios of (A) general and health-specific internet use, and (B) health-specific internet use stratified by sex. The primary independent variable with adjusted odds ratios displayed in the figure is healthcare satisfaction. Other variables included in the model were year of survey, age, sex, sexual orientation, region, years since diagnosis, race/ethnicity, marital status, educational attainment, citizenship status, socioeconomic status, self-reported health status, and health insurance coverage status.

${ }^{\star} P \leq 05$ (referent group $=$ very satisfied with healthcare). Solid bars represent $95 \%$ confidence intervals.

However, participants who reported a history of cancer were subsequently asked for their cancer type and age at diagnosis, thus potentially limiting the rate of errors in self-report. Second, there was no information on whether "health information" online searches were specifically related to cancer diagnosis or treatments. However, given the ongoing information needs among the cancer survivor population, ${ }^{3}$ it is likely that cancer-related queries represent a large proportion of their online health-information searches. Third, there was no detail on how long or how frequently cancer survivors used the internet for their general or health-specific information. Fourth, the NHIS survey does not provide information on cancer status and treatment details, which could affect both information needs and healthcare satisfaction. Furthermore, internet use, both general and health-specific, were self-reported in the NHIS survey, and not verified by methods such as tracking internet browsing history. It is possible that participants could have forgotten previously conducted online health searches or even purposefully chosen not to reveal this to the person conducting the survey, although we cannot readily surmise a rationale for withholding this information.

\section{Conclusions}

We found that an increasing proportion of survivors of cancer use the internet for health-specific information, an association that was greater among women who reported dissatisfaction with healthcare. Given the overall high prevalence of internet use to obtain health information among cancer survivors, physicians, healthcare organizations, and other cancer advocacy groups should participate in efforts to produce high-quality, reliable online health-related materials. As online health informationseeking becomes more pervasive, strategies should be implemented to help providers better care for internetinformed patient, including directing patients to peerreviewed, reputable web pages. In addition, efforts should also be made to improve cancer survivors' ability to appraise and integrate online health information into their care.

\section{Acknowledgments}

The authors would like to thank Marie Gabrielle Dee, Gabriel B. Borja, and Carolyn H. Cong for assistance with proofreading the manuscript.

Submitted January 1, 2020; accepted for publication May 12, 2020.

Author contributions: Study concept and design: All authors. Data analysis and interpretation: Dee, Muralidhar, Butler, Sha, Mahal, Nguyen, Sanford. Manuscript preparation: Dee, Sanford. Critical revision: Muralidhar, Butler, Yu, Sha, Mahal, Nguyen.

Disclosures: Dr. Nguyen has disclosed that he receives grant/research support from Bayer, Astellas, Ferring, Dendreon, Blue Earth, Genome Dx, Augmenix, Boston Scientific, Janssen, and Cota Healthcare. The remaining authors have disclosed that they have not received any financial consideration from any person or organization to support the preparation, analysis, results, or discussion of this article.

Correspondence: Nina N. Sanford, MD, Department of Radiation Oncology, University of Texas Southwestern Medical Center, 2280 Inwood Road, Dallas, TX 75390-9303. Email: Nina.Sanford@UTSouthwestern.edu 


\section{References}

1. de Moor JS, Mariotto AB, Parry $C$, et al. Cancer survivors in the United States: prevalence across the survivorship trajectory and implications for care. Cancer Epidemiol Biomarkers Prev 2013;22:561-570.

2. DeSantis $C E$, Lin $C C$, Mariotto $A B$, et al. Cancer treatment and survivorship statistics, 2014. CA Cancer J Clin 2014;64:252-271.

3. Playdon M, Ferrucci LM, McCorkle R, et al. Health information needs and preferences in relation to survivorship care plans of long-term cancer survivors in the American Cancer Society's Study of Cancer Survivors-I. J Cancer Surviv 2016;10:674-685.

4. Gansler T, Kepner J, Willacy E, et al. Evolving information priorities of hematologic cancer survivors, caregivers, and other relatives. J Cancer Educ 2010;25:302-311

5. Harrison JD, Young JM, Price MA, et al. What are the unmet supportive care needs of people with cancer? A systematic review. Support Care Cancer 2009;17:1117-1128.

6. McDowell ME, Occhipinti S, Ferguson M, et al. Predictors of change in unmet supportive care needs in cancer. Psychooncology 2010;19:508-516.

7. Arora NK, Johnson P, Gustafson DH, et al. Barriers to information access, perceived health competence, and psychosocial health outcomes: test of a mediation model in a breast cancer sample. Patient Educ Couns 2002; 47:37-46

8. Kent EE, Arora NK, Rowland $\mathrm{JH}$, et al. Health information needs and health-related quality of life in a diverse population of long-term cancer survivors. Patient Educ Couns 2012;89:345-352.

9. Husson O, Mols F, van de Poll-Franse LV. The relation between information provision and health-related quality of life, anxiety and depression among cancer survivors: a systematic review. Ann Oncol 2011;22:761-772.

10. Booth K, Beaver K, Kitchener H, et al. Women's experiences of information, psychological distress and worry after treatment for gynaecological cancer. Patient Educ Couns 2005;56:225-232.

11. Hesse BW, Greenberg AJ, Rutten LJF. The role of Internet resources in clinical oncology: promises and challenges. Nat Rev Clin Oncol 2016;13:767-776.

12. Pew Research Center. Internet/Broadband fact sheet. Accessed August 31, 2020. Available at: https://www.pewresearch.org/internet/fact-sheet/ internet-broadband/

13. Shim M, Kelly B, Hornik R. Cancer information scanning and seeking behavior is associated with knowledge, lifestyle choices, and screening. J Health Commun 2006;11(Suppl 1):157-172.

14. Dee EC, Lee G. Adverse effects of radiotherapy and chemotherapy for common malignancies: what is the quality of information patients are finding online? [published online September 2, 2019]. J Cancer Educ, doi. org/10.1007/s13187-019-01614-2

15. Dee EC, Varady NH. Radiation oncology online: quality, strategies, and disparities [published online June 3, 2019]. J Cancer Educ, doi.org/ 10.1007/s13187-019-01553-y

16. Corkum MT, Liu W, Palma DA, et al. Online advertising and marketing claims by providers of proton beam therapy: are they guideline-based? Radiat Oncol 2018;13:43

17. Lawrentschuk N, Sasges D, Tasevski R, et al. Oncology health information quality on the Internet: a multilingual evaluation. Ann Surg Oncol 2012; 19:706-713.

18. Varady NH, Dee EC, Katz JN. International assessment on quality and content of internet information on osteoarthritis. Osteoarthritis Cartilage 2018;26:1017-1026.

19. Dee EC, Varady NH, Katz JN, et al. Disparity in online health information in pediatric vs. adult surgical conditions. Pediatr Surg Int 2019;35:813-821.

20. Meric F, Bernstam EV, Mirza NQ, et al. Breast cancer on the world wide web: cross sectional survey of quality of information and popularity of websites. BMJ 2002;324:577-581.

21. Grewal $P$, Alagaratnam $S$. The quality and readability of colorectal cancer information on the internet. Int J Surg 2013;11:410-413.

22. Storino A, Castillo-Angeles M, Watkins AA, et al. Assessing the accuracy and readability of online health information for patients with pancreatic cancer. JAMA Surg 2016;151:831-837.

23. Amalraj S, Starkweather C, Nguyen C, et al. Health literacy, communication, and treatment decision-making in older cancer patients. Oncology (Williston Park) 2009;23:369-375

24. Tan SSL, Goonawardene N. Internet health information seeking and the patient-physician relationship: a systematic review. J Med Internet Res 2017;19:e9.
25. Chen YY, Li CM, Liang JC, et al. Health information obtained from the internet and changes in medical decision making: questionnaire development and cross-sectional survey. J Med Internet Res 2018;20:e47.

26. Centers for Disease Control and Prevention. National health interview survey: methods. Accessed August 31, 2020. Available at: https://www. cdc.gov/nchs/nhis/methods.htm

27. Ruggles S, Flood S, Goeken R, et al. Integrated Public Use Microdata Series USA: Version 9.0 [Dataset]. University of Minnesota; 2019. Accessed August 31, 2020. Available at: https://doi.org/10.18128/D010 V9.0

28. Sanford NN, Lam MB, Butler SS, et al. Self-reported reasons and patterns of noninsurance among cancer survivors before and after implementation of the Affordable Care Act, 2000-2017. JAMA Oncol 2019;5:e191973.

29. Nipp RD, Shui AM, Perez GK, et al. Patterns in health care access and affordability among cancer survivors during implementation of the af fordable care act. JAMA Oncol 2018;4:791-797.

30. Gonzales F, Zheng Z, Yabroff KR. Trends in financial access to prescription drugs among cancer survivors. J Natl Cancer Inst 2018;110:216-219.

31. Yabroff KR, Lawrence WF, Clauser $\mathrm{S}$, et al. Burden of illness in cancer survivors: findings from a population-based national sample. J Natl Cancer Inst 2004;96:1322-1330.

32. Heerdegen ACS, Petersen GS, Jervelund SS. Determinants of patient satisfaction with cancer care delivered by the Danish healthcare system. Cancer 2017:123:2918-2926.

33. Faller H, Koch U, Brähler E, et al. Satisfaction with information and unmet information needs in men and women with cancer. J Cancer Surviv 2016; 10:62-70.

34. von Elm E, Altman DG, Egger M, et al. The strengthening the reporting of observational studies in epidemiology (STROBE) statement: guidelines for reporting observational studies. Int J Surg 2014;12 1495-1499.

35. Hartzband P, Groopman J. Untangling the Web-patients, doctors, and the internet. N Engl J Med 2010;362:1063-1066.

36. Helft PR, Hlubocky F, Daugherty CK. American oncologists' views of internet use by cancer patients: a mail survey of American Society of Clinical Oncology members. J Clin Oncol 2003;21:942-947.

37. Finney Rutten LJ, Agunwamba AA, Wilson P, et al. Cancer-related in formation seeking among cancer survivors: trends over a decade (2003-2013). J Cancer Educ 2016:31:348-357.

38. Foster $\mathrm{C}$, Breckons $\mathrm{M}$, Cotterell $\mathrm{P}$, et al. Cancer survivors' self-efficacy to self-manage in the year following primary treatment. J Cancer Surviv 2015:9:11-19.

39. Cunningham AJ, Lockwood GA, Cunningham JA. A relationship between perceived self-efficacy and quality of life in cancer patients. Patient Educ Couns 1991; 17:71-78

40. Eysenbach G, Köhler C. How do consumers search for and appraise health information on the world wide web? Qualitative study using focu groups, usability tests, and in-depth interviews. BMJ 2002;324:573-577.

41. Eysenbach G, Köhler C. Does the internet harm health? Database of adverse events related to the internet has been set up. BMJ 2002;324:239.

42. Norman CD, Skinner HA. eHealth literacy: essential skills for consumer health in a networked world. J Med Internet Res 2006;8:e9.

43. Norman CD, Skinner HA. eHEALS: the eHealth Literacy Scale. J Med Internet Res 2006;8:e27

44. van der Vaart $\mathrm{R}$, van Deursen AJ, Drossaert $\mathrm{CHC}$, et al. Does the eHealth Literacy Scale (eHEALS) measure what it intends to measure? Validation of a Dutch version of the eHEALS in two adult populations. J Med Internet Res 2011;13:e86.

45. Tran BNN, Singh M, Singhal D, et al. Readability, complexity, and suitability of online resources for mastectomy and lumpectomy. J Surg Res 2017:212:214-221.

46. Sha ST, Perni S, Muralidhar V, et al. Trends, quality, and readability of online health resources on proton radiation therapy. Int J Radiat Oncol Biol Phys 2020;107:33-38

47. Jefford $M$, Tattersall MHN. Informing and involving cancer patients in thei own care. Lancet Oncol 2002;3:629-637.

48. Hesse BW, Nelson DE, Kreps GL, et al. Trust and sources of health information: the impact of the Internet and its implications for health care providers: findings from the first Health Information National Trends Survey. Arch Intern Med 2005;165:2618-2624. 